\title{
A MIGRAÇÃO CONTEMPORÂNEA EM MATO GROSSO DO SUL
}

\begin{abstract}
Arlinda Cantero Dorsa
Doutora em Língua Portuguesa, docente do Mestrado e Doutorado em Desenvolvimento Local, Universidade Católica Dom Bosco (UCDB), Campo Grande, MS, Brasil. acdorsa@uol.com.br

Michele Nakazato

Doutoranda em Desenvolvimento Local, Universidade Católica Dom Bosco (UCDB), Campo Grande, MS, Brasil. michelenakazato@hotmail.com.

Thiago Henrique Conde Britts Mestrando em Desenvolvimento Local, Universidade Católica Dom Bosco (UCDB), Campo Grande, MS, Brasil. thiago_britts@hotmail.com.
\end{abstract}

\begin{abstract}
RESUMO
As reflexões produzidas sobre os problemas sociais contemporâneos, com relação aos estudos migratórios nos últimos anos é uma realidade que vem inspirando muitos pesquisadores ao aprofundamento dessa discussão. Neste prisma, este artigo apresenta um estudo sobre a migração contemporânea em Mato Grosso do Sul, partindo-se da questão norteadora sobre qual é a realidade da migração no estado do MS. Objetiva, portanto, a partir de um estudo exploratório, bibliográfico e documental, aprofundar a realidade vivida no MS sobre esta temática. Com relação aos estudos bibliográficos, apresenta uma tipologia conceitual sobre migração, refugiados, suas implicações no território e territorialidade e possibilidades do receber e acolher. Infere-se dessa pesquisa que há uma necessidade de se promover a possibilidade de redução do preconceito e discriminação em relação aos imigrantes, desenvolvendo um equilíbrio humanitário no novo território que o acolhe para a formação de uma nova territorialidade e que contribua para o desenvolvimento local.
\end{abstract}

Palavras-chave: Migrações; Refugiados; Território e territorialidade; MS 


\section{ABSTRACT}

\section{CONTEMPORARY MIGRATION IN MATO GROSSO DO SUL}

The reflections produced on contemporary social problems, with respect to migration studies in recent years is a reality that has inspired many researchers to deepen this discussion. In this perspective, this article presents a study on contemporary migration in Mato Grosso do Sul, starting from the guiding question of what is the reality of migration in the state of MS. It aims, therefore, from an exploratory, bibliographical, and documental study, to deepen the reality experienced in MS on this theme. Regarding the bibliographical studies, it presents a conceptual typology about migration, refugees, their implications on the territory and territoriality and possibilities of receiving and welcoming. It is inferred from this research that there is a need to promote the possibility of reducing prejudice and discrimination against immigrants, developing a humanitarian balance in the new territory that receives them for the formation of a new territoriality and that contributes to local development.

Keywords: Migrations; Refugees; Territory and territoriality; MS

Recebido em: 23/09/2021. Aceito em: 16/12/2021 


\section{INTRODUÇÃO}

A presença dos migrantes no Estado de Mato Grosso do Sul é uma realidade que inspira reflexões sobre problemas sociais contemporâneos. Uma das questões prementes é a relação da migração para refúgio nos últimos anos. A pessoa que sai de seu país e não tem como retornar por motivos políticos, de guerras, conflitos, perseguição, entre outras razões, é considerada "refugiada".

Conforme Almeida (2017, p. 25), “a palavra 'refúgio' tem um sentido cada vez mais significativo para o momento contemporâneo, pois retrata que o mundo ainda não conseguiu resolver seus problemas mais primários do passado". Com isso, a pesquisadora reafirma que a temática refúgio é um problema social que o mundo está enfrentando pois segundo seu pensamento "são milhões de pessoas fugindo, buscando abrigo e necessitando de ajuda" (ALMEIDA, 2017, p. 25). Nesse prisma, essa é a realidade de muitos que vivem no estado sulmato-grossense.

Assim como existe aquele que está em fuga, existe aquele que recebe, que acolhe o que vive a triste realidade da fuga de seu território para viver em território com uma cultura totalmente diferente. Para analisar esta realidade, este estudo traz uma discussão inicial sobre migração, refugiados, suas implicações no território e territorialidade a partir de uma abordagem quantitativa e qualitativa e pesquisa bibliográfica e documental.

\subsection{AS TIPOLOGIAS CONCEITUAIS SOBRE MIGRANTES E REFUGIADOS}

Os exercícios na elaboração de fronteiras conceituais de definição de determinados temas é uma tarefa difícil que muitas vezes pendem para tarefas inclusivas ou exclusivas, principalmente quando os exercícios se voltam às definições relacionadas a Migrações e Refugiados. Há dois polos extremos que variam entre definição ampla que inclui diferentes formas de mobilidade e do outro restrita, excluindo determinados movimentos, pois de acordo com Peixoto (1998, p.13), "apesar de ser fácil distinguir, em certos contextos, um 'migrante' de um 'não migrante', a quantidade de situações 'mistas' coloca problemas inesperados a uma definição do termo".

O estudo das Migrações implica uma cronologia retomando o ano de 1925, quando Fairchild, clarificando as diferentes formas de deslocação humana, apresentou quatro tipos de mobilidade: i) invasão - exemplificando os Visigodos durante o império romano; ii) 
conquista - resultante da iniciativa dos povos com cultura superior; iii) colonização descoberta e submissão dos povos mais débeis; iv) imigração - deslocamento pacífico dos indivíduos entre países. Segundo o autor "as causas para estes distintos movimentos migratórios têm que ser muito poderosas, porque a tendência do ser humano é permanecer no local ao qual pertence". (FAIRCHILD, 1925: 2 e 9).

Já em 1958, Petersen apresenta cinco tipos de migrações i) primitiva - suscitadas pelas condições ecológicas; ii) forçada - determinismo do estado ou outra instituição social; iii) impelida - a decisão do ato migratório cabe aos indivíduos; iv) livre - decisão ainda dependente da vontade individual ainda que de forma reduzida; v) massiva - pela condução coletiva expressa por vontade migratória.(PETERSEN, 1958)

Um terceiro estudo foi feito em 1991 por Appleyard, ao elaborar uma tipologia migratória internacional compreendendo seis tipos: i) migrantes permanente - fixação definitiva no local a que se destinou; ii) trabalhadores contratados temporários-, limitação de permanência podendo se converter em permanente; iii) profissionais qualificados de circulação temporária - mobilidades pertencentes a empresas transnacionais; iv) trabalhadores clandestinos ou ilegais; v) migrantes demandantes de asilo político; vi) refugiados circunstanciais relacionados a fatos políticos ou ambientais.

Uma conceituação mais recente foi elaborada por Portes em 1998, ao desenvolver três diferentes tipos de níveis de incorporação do migrante nas comunidades, a qual se destinou: i) política imigratória desenvolvida pelo governo; ii) atitude da sociedade relativamente à recepção de migrantes; iii) comunidade étnica de pertença no país de destino.

Amplia esta concepção, Cohen, em 2005, quando afirma que ainda que tenha havido as restrições, controles e formas seletivas de migrações, estas tiveram um sensível aumento, podendo atualmente serem distinguidos cerca de oito tipos migratórios:

migrações de trabalhadores legais; migração de trabalhadores ilegais ou indocumentados; migração de refugiados e de pessoas deslocadas; migração feminina independente; trabalhadores migrantes especializados passageiros; trabalhadores migrantes especializados de longa duração; movimentos internos em grande escala; turismo (COHEN, 2005: 33-37).

A partir dessas diferenciações, percebe-se então, um sensível aumento de possibilidades migratórias que abrem um leque de tipologias implicando assim não só em adaptações aos países que os recebe como também nas amplas condições de trabalho nesses países. 
Desde as recomendações em 1953, da Organização das Nações Unidas (ONU), ser migrante portanto, deveria atender à permanência de no máximo um ano no estrangeiro; em 1998, a entidade passou a estabelecer uma diferenciação entre migrante de longa data e de curta duração, diferença estabelecida pelo limite dos 12 meses de permanência ou não no estrangeiro.

Dada à dificuldade de conceituação de forma clara e objetiva, é importante que possamos apresentar uma definição das expressões que permeiam o universo das Migrações e Refugio com o objetivo de clarear estas distinções, já com um olhar mais contemporâneo e cima de tudo elucidativo.

Apoiamo-nos então no Relatório intitulado "Percursos, percalços e perspectivas: a jornada do projeto Atuação em Rede: capacitação dos atores envolvidos no acolhimento, na integração e na interiorização de refugiados e migrantes no Brasil, organizado pela Escola Superior do Ministério Público da União (ESMPU) e Alto comissariado das Nações Unidas para os Refugiados (ACNUR) publicado em 2020. Serviu também de embasamento teórico o Relatório mensal do OBMigra de 2020, Observatório das Migrações Internacionais de autoria de Cavalcanti (et al, 2020).

De acordo com os referidos relatórios e artigo publicado, podemos utilizar as seguintes tipologias para conceituar o universo que envolve as Migrações e Refugiados, de acordo com o Quadro 1 abaixo:

Quadro 1 - Tipologias conceituais (ESMPU/ACNUR)

\begin{tabular}{|l|l|}
\hline Tipologia & Conceito \\
\hline Migrante & $\begin{array}{l}\text { qualquer pessoa que está se movimentando, ou já se movimentou, através de } \\
\text { uma fronteira internacional ou dentro de um Estado, saindo do seu lugar habitual } \\
\text { de residência, independentemente da situação jurídica da pessoa; se o } \\
\text { deslocamento foi voluntário ou involuntário; quais foram os motivos para esse } \\
\text { deslocamento; ou a duração de sua estada. }\end{array}$ \\
\hline Imigrante: & $\begin{array}{l}\text { pessoa nacional de outro país ou apátrida que trabalha ou reside e se estabelece } \\
\text { temporária ou definitivamente em um país. }\end{array}$ \\
\hline Emigrante & pessoa que se estabelece temporária ou definitivamente no exterior \\
\hline
\end{tabular}




\begin{tabular}{|l|l|}
\hline $\begin{array}{l}\text { Residente } \\
\text { fronteiriço }\end{array}$ & $\begin{array}{l}\text { pessoa nacional de país limítrofe ou apátrida que conserva a sua residência } \\
\text { habitual em município fronteiriço de país vizinho. }\end{array}$ \\
\hline Visitante & $\begin{array}{l}\text { pessoa nacional de outro país ou apátrida que vão a um país para estadas de } \\
\text { curta duração, sem pretensão de se estabelecer temporária ou definitivamente } \\
\text { no território nacional. }\end{array}$ \\
\hline Refugiado & $\begin{array}{l}\text { pessoa que está fora de seu país de nacionalidade devido a fundados temores de } \\
\text { perseguição relacionados a questões de raça, religião, nacionalidade, } \\
\text { pertencimento a um determinado grupo social ou opinião política, como também } \\
\text { devido a grave e generalizada violação de direitos humanos e conflitos armados. }\end{array}$ \\
\hline $\begin{array}{l}\text { Solicitante da } \\
\text { condição } \\
\text { refugiado }\end{array}$ & $\begin{array}{l}\text { de } \\
\text { pessoa que solicita às autoridades competentes ser reconhecida como refugiada, } \\
\text { mas que ainda não teve seu pedido avaliado definitivamente pelas autoridades } \\
\text { competentes. }\end{array}$ \\
\hline Apátrida & $\begin{array}{l}\text { pessoa que não é considerada como seu nacional por qualquer Estado, segundo a } \\
\text { sua legislação, seja por discriminação contra determinados grupos étnicos ou } \\
\text { religiosos ou com base no gênero; surgimento de novos Estados e transferências } \\
\text { de território entre Estados existentes; e lacunas nas leis de nacionalidade. }\end{array}$ \\
\hline
\end{tabular}

Fonte: ESMPU; ACNUR; OBMigra, 2020. Reelaboração dos autores

De acordo com o Relatório do Observatório das Migrações Internacionais (OBMigra), de autoria de Cavalcanti (et al, 2020), algumas definições como imigrante, emigrante, residente fronteiriço, visitante e apátrida, seguidas pelo referido órgão, segue o estabelecido no Art,10 da Lei n. 13.445/2017, que dispõe sobre os direitos e os deveres do migrante e do visitante, regula a sua entrada e estada no País e estabelece princípios e diretrizes para as políticas públicas para o emigrante.

$\S 1$ O Para os fins desta Lei, considera-se:

I - (VETADO);

II - imigrante: pessoa nacional de outro país ou apátrida que trabalha ou reside e se estabelece temporária ou definitivamente no Brasil;

III- emigrante: brasileiro que se estabelece temporária ou definitivamente no exterior;

IV -residente fronteiriço: pessoa nacional de país limítrofe ou apátrida que conserva a sua residência habitual em município fronteiriço de país vizinho;

V - visitante: pessoa nacional de outro país ou apátrida que vem ao Brasil para estadas de curta duração, sem pretensão de se estabelecer temporária ou definitivamente no território nacional;

$\mathrm{VI}$ - apátrida: pessoa que não seja considerada como nacional por nenhum Estado, segundo a sua legislação, nos termos da Convenção sobre o Estatuto dos Apátridas, de 1954, promulgada pelo Decreto o 4.246, de 22 de maio de 2002, ou assim reconhecida pelo Estado brasileiro. 
Segundo a Lei no 9.474, de 22 de julho de 1997, na condição de refugiados segundo o Art. 1으, será reconhecido como refugiado todo indivíduo que:

\footnotetext{
I - devido aos fundados temores de perseguição por motivos de raça, religião, nacionalidade, grupo social ou opiniões políticas encontre-se fora de seu país de nacionalidade e não possa ou não queira acolher-se à proteção de tal país;

II - não tendo nacionalidade e estando fora do país onde antes teve sua residência habitual, não possa ou não queira regressar a ele, em função das circunstâncias descritas no inciso anterior; III - devido a grave e generalizada violação de direitos humanos, é obrigado a deixar seu país de nacionalidade para buscar refúgio em outro país.
}

O estudo das Migrações, seus movimentos e sua complexidade política, cultural, ambiental e econômica, requer, portanto, análises de outras áreas da pesquisa, como aquelas que buscam no contexto geográfico o entendimento de territórios e territorialidades e suas implicações no desenvolvimento local.

\subsection{TERRITÓRIO E TERRITORIALIDADE}

Os deslocamentos humanos sempre ocorreram e são diversos os motivos pelos quais os indivíduos decidem mudar: catástrofes naturais, problemas econômicos ou políticos, guerras ou motivações pessoais. Nessas mudanças, fatores culturais são transportados e passam a circular em outros territórios.

O geógrafo Rogério Haesbaert (2020) traz em seus estudos o conceito de território, o pesquisador vai buscar na etimologia da palavra e nos apresenta territorium em latim, derivada do vocábulo latino terra. Segundo o autor, a palavra terra, no século IV "era utilizada pelo sistema jurídico romano dentro do chamado jus terrendi", concepção esta trazida por Di Méo (1998, p. 47) e se "confundia com o 'direito de aterrorizar' (terrifier, em francês)" (Ibdem). Conforme Haesbaert, (2020) território era a porção apropriada de terra estabelecida dentro de uma determinada jurisdição político-administrativa. De acordo com o referido autor, das várias noções de território pode-se agrupar as concepções em quatro vertentes:

Vertente 1 - política: refere-se às relações espaço-poder ou jurídico-política (relacionada ao espaço-poder institucional). É a vertente mais difundida, onde o território é um espaço delimitado e controlado, que exerce um determinado poder, muitas vezes relacionado ao poder político do Estado. 
Vertente 2 - cultural ou simbólico-cultural: refere-se a dimensão simbólica e mais subjetiva de território; e é entendida como um produto da apropriação/valorização de um grupo em relação ao espaço vivido.

Vertente 3 - econômica: é a vertente menos difundida aonde a dimensão espacial das relações econômicas e o território são vistos como fonte de recursos e/ou embates de classes sociais e na relação capital-trabalho, como a divisão territorial do trabalho.

Vertente 4 - natural: a mais antiga e pouco veiculada nas Ciências Sociais. Refere-se às relações entre sociedade e natureza, especialmente ao comportamento do homem em relação ao seu ambiente físico.

Ao apontar as quatro dimensões de análise de território, o pesquisador destaca que existem outras definições para análise. Assim, também traz em seus estudos a perspectiva materialista de território, aquela que "tem uma conotação fortemente vinculada ao espaço físico, à terra" (HAESBAERT, 2020, p. 42). Enfatizando as características materiais e imateriais, Radomsky, et al. (2016, p. 114), destaca que "os territórios são estabelecidos a partir das características materiais e imateriais, ou seja, com base em seus recursos biofísicos e humanos, suas relações sociais, e seus modos de produção e cultura".

Santos (2020, p. 96), define território como "chão e mais a população, isto é, uma identidade, o fato e o sentimento de pertencer àquilo que nos pertence". Para o autor, território é mais do que um composto de sistemas naturais e de coisas produzidas pelas pessoas; é "a base do trabalho, da residência, das trocas materiais e espirituais e da vida, sobre os quais ele influi" (SANTOS, 2020, p. 96).

A partir do conceito de território, tem-se reflexões sobre territorialidade. Segundo Saquet (2008), a territorialidade representa a qualidade que o território adquire conforme sua utilização ou apreensão pelo ser humano. De acordo com o autor, "corresponde às ações humanas, ou seja, à tentativa de um indivíduo ou grupo para controlar, influenciar ou afetar objetos, pessoas e relações numa área delimitada" (SAQUET, 2008, p. 86). Nos estudos de Bomtempo e Sposito (2008), questões sobre a territorialidade são descritas a partir de observações dos fluxos migratórios entre o Japão e o Brasil.

Os estudos demonstram sobre como os migrantes japoneses e brasileiros deixaram seu território de origem e o consequente "contato com outro território e a formação de novas territorialidades como condição e meio para a sua permanência no Brasil" (BOMTEMPO e SPOSITO, 2008, p. 230). Trazem em seu bojo as relações sociais da territorialidade e o ganho 
adquirido em uma área limitada, que é o território e como podemos perceber a presença e inserção dos refugiados em seus processos migratórios. Neste sentido, busca-se aprofundar os estudos e compreender os fluxos migratórios sob o olhar jurídico-administrativo.

\section{O RECEBER E ACOLHER NAS MIGRAÇÕES E REFUGIADOS SOB A ÓTICA DOS DADOS E LEGISLAÇÕES}

$\mathrm{Na}$ atualidade, segundo relatório do Alto Comissariado das Nações Unidas para Refugiados, no ano de 2017, mais de 68 milhões de pessoas no mundo todo foram forçadas a se deslocar de seus países de origem, por diferentes motivos, como guerras, conflitos armados, perseguições e desastres; considerando-se como um problema mundial que carece de medidas imediatas.

Essas pessoas denominadas de refugiados, que segundo o artigo 1으 da Lei 9.474/1997, são caracterizadas como pessoas que se encontram fora de seu país de nacionalidade, e que não podem ou não querem acolher-se à proteção de tal país; ou em decorrência de violação dos direitos humanos de forma generalizada, são obrigadas assim a deixar seu país de origem para buscar refúgio em outros países.

No Brasil, a legislação tem como base a Convenção de Genebra, ocorrida no ano de 1951 pela ONU (Organização das Nações Unidas), assim como pela Declaração de Cartagena, publicada em 1984, acrescentando os temos "grave e generalizada" violação dos direitos humanos, possibilitando muitas interpretações sobre seu conceito, e sua proteção no país de acolhimento.

Desse modo, considera-se que os refugiados saem de seu país de origem em busca de proteção contra os motivos supracitados, em cinco áreas apontadas pela legislação: religião, nacionalidade, raça, grupo social e opinião política. Além disso, também existem os tipos de violência generalizada e perseguições que podem se combinar à questões de cunho social e econômico, denominados de "migrações internacionais mistas" e também de "migrações internacionais multicausais".

O Brasil, por suas dimensões continentais e suas diversas fronteiras com a maioria dos países da América do Sul, acaba recebendo uma grande quantidade de imigrantes por suas fronteiras secas, especialmente na região Centro-Oeste do país e no estado de Mato Grosso 
do Sul (MS), tendo como principais municípios de entrada as regiões de Corumbá, Dourados, Ponta Porã, Mundo Novo e outros, que se localizam nas fronteiras com Bolívia e Paraguai.

Assim, nessas regiões do MS, já existe uma dinâmica de mobilidade humana principalmente nas cidades da região fronteiriça, que recebem imigrantes da América Latina, como bolivianos, haitianos e paraguaios, que são os maiores solicitantes de refúgio do país. Nessa perspectiva, o Brasil e o estado do MS, na atualidade fazem parte do fenômeno internacional das migrações, com enorme relevo no sistema internacional de Estados.

A partir desse contexto, foi construído o Comitê Estadual para Refugiados, Migrantes e Apátridas (CERMA-MS), que busca consolidar as diretrizes de defesa dos direitos humanos, para a construção de políticas de proteção a essas pessoas. Em razão do exposto, considerase que por ser um local de passagem de imigrantes e refugiados, a região de fronteira do Estado do Mato Grosso do Sul, configura-se como espaço para a criação de instituições de políticas públicas, caracterizando-se como um potencial para o país, no sentido de solucionar os problemas atuais para os migrantes internacionais.

Da mesma forma, outra estratégia para solucionar as demandas atuais, seria a busca pela realização de diagnósticos e levantamento de dados, como os de atendimento em postos de saúde, matrícula de estudantes migrantes, refugiados, bem como de solicitantes de refúgio nas escolas do MS, no sentido de identificar os municípios e regiões do país com maior e menor concentração, para assim planejar-se estratégias específicas e diretas considerando as características e especificidades de cada contexto populacional.

\subsection{REALIDADE DOS REFUGIADOS: DA REALIDADE MUNDIAL A MATO GROSSO DO SUL}

O ato de migrar corresponde à movimentação espacial da população. O migrante troca de país, de Estado, região, ou até de domicílio e este processo de migração ocorre desde o início da história da humanidade, sendo que a categoria de migração de refugiados está ligada a pessoas que escaparam de conflitos armados ou perseguições.

Esses conflitos colocam em uma situação muito perigosa e intolerável a vida das pessoas que devem cruzar fronteiras internacionais para buscar segurança nos países mais próximos e então se tornarem um 'refugiado' reconhecido internacionalmente, com o acesso à assistência dos Estados, do ACNUR (Alto Comissariado das Nações Unidas para Refugiados) e de outras organizações. 
O direito internacional define e protege os refugiados. Nesse sentido, atuam a Convenção da ONU de 1951 sobre o Estatuto dos Refugiados e seu protocolo de 1967, assim como a Convenção da OUA (Organização da Unidade Africana) - pela qual se regularam os aspectos específicos dos problemas dos refugiados na África em 1969 - ou a Declaração de Cartagena de 1984 sobre os Refugiados, que continuam sendo a chave da atual proteção dos refugiados (ACNUR).

Segundo o Instituto de Pesquisa Econômica Aplicada (IPEA) existe um crescente fluxo de imigrantes haitianos, sírios e congoleses que passam a ter diariamente seu futuro e sua vida ameaçados pelo aumento da violência e desrespeito aos direitos humanos, sendo forçados a deixarem o seu país e buscarem refúgio no Brasil. Para PEREIRA JUNIOR (2020, p. 09):

[...] o Brasil mantém registros históricos da presença de refugiados, ainda que não se apresente como destino preferencial de refúgio, tornando-se, entretanto, um destino possível diante das barreiras cada vez mais consolidadas para o ingresso de deslocados com baixa qualificação laboral em países tradicionalmente recipiendários desses fluxos de imigrantes.

Vale ressaltar que o território brasileiro é composto e formado por imigrantes, um país de misturas étnicas e culturais. Existe na atualidade um novo fluxo migratório de pessoas que buscam melhores condições de vida, fugindo de crises econômicas, guerras civis e buscando emprego. Nas últimas décadas, o Brasil passou a ser procurado por diversos grupos migratórios do Haiti, Venezuela, Senegal, República Democrática do Congo e da Síria.

De fato, os últimos anos foram marcados por um crescente número de solicitações e concessões de refúgio no Brasil. Em janeiro de 2019, havia um total de 161.057 solicitações de refúgio em trâmite e, até dezembro de 2018, um acumulado de 11.231 refugiados reconhecidos no país, sendo que em 2014 esse número somava 7.262 pessoas (BRASIL, 2018).

Quadro 2 - Panorama mundial do deslocamento forçado em 2019

\begin{tabular}{|c|c|}
\hline \multicolumn{2}{|c|}{$\begin{array}{l}\text { Deslocados forçados no mundo } \\
79,5 \text { milhöes de pessoas }\end{array}$} \\
\hline Deslocados Internos (IDP's) & 45.7 milhões de pessoas \\
\hline Refugiados sob o mandato do ACNUR & 20.4 milhões de pessoas \\
\hline Refugiados sob o mandato do UNRWA & 5.6 milhöes de pessoas \\
\hline Solicitantes de refúgio & 4.2 milhöes de pessoas \\
\hline Venezuelanos deslocados no exterior & 3.6 milhões de pessoas \\
\hline
\end{tabular}


Fonte: elaborado pelo OBMigra a partir dos dados do Alto Comissariado das Nações Unidas para os Refugiados (ACNUR, 2020).

A partir da análise da movimentação de trabalhadores solicitantes de reconhecimento da condição de refugiados se verifica uma mudança de inserção desses trabalhadores no mercado de trabalho formal no Brasil ao longo da década. A geografia do refúgio no Brasil passou por muitas transformações importantes com a distribuição de pessoas solicitantes de reconhecimento da condição de refugiados no território brasileiro segundo a grande capacidade de atração do mercado de trabalho nas áreas de maior dinamismo do país. (SILVA, G.J - OBMigra, 2020).

Quadro 3 - Número de solicitantes de reconhecimento da condição de refugiado, segundo principais países de nascimento, Brasil - 2019.

\begin{tabular}{|l|c|}
\hline \multicolumn{1}{|c|}{ País de nascimento } & $\mathbf{2 0 1 9}$ \\
\hline Total & $\mathbf{8 2 . 5 5 2}$ \\
\hline Venezuela & 53.713 \\
\hline Haiti & 16.610 \\
\hline Cuba & 3.999 \\
\hline China & 1.486 \\
\hline Bangladesh & 738 \\
\hline Angola & 603 \\
\hline Síria & 429 \\
\hline Colômbia & 381 \\
\hline Senegal & 363 \\
\hline Nigéria & 331 \\
\hline Índia & 312 \\
\hline Marrocos & 229 \\
\hline Guiné Bissau & 205 \\
\hline Líbano & 196 \\
\hline R.D. Congo & 167 \\
\hline Paquistão & 165 \\
\hline Gana & 155 \\
\hline Outros & 2.470 \\
\hline
\end{tabular}

Fonte: Elaborado pelo OBMigra, a partir dos dados da Polícia Federal, solicitações de reconhecimento da condição de refugiado - Brasil, 2019.

No quadro 3 , verifica-se que o maior número de solicitação de reconhecimento da condição de refugiado, em 2019, é de venezuelanos com 82.552 pedidos; seguido dos haitianos com 16.610 pedidos; dos cubanos com 3.999; e dos chineses com 1.486 solicitações. Depois tem-se pedidos de pessoas de Bangladesh, Angola, Síria, Colômbia, Senegal, entre outros países. 


\section{Gráfico 1 - Número de solicitações de reconhecimento da condição de refugiado, segundo} ano, Brasil, 2011 - 2019.

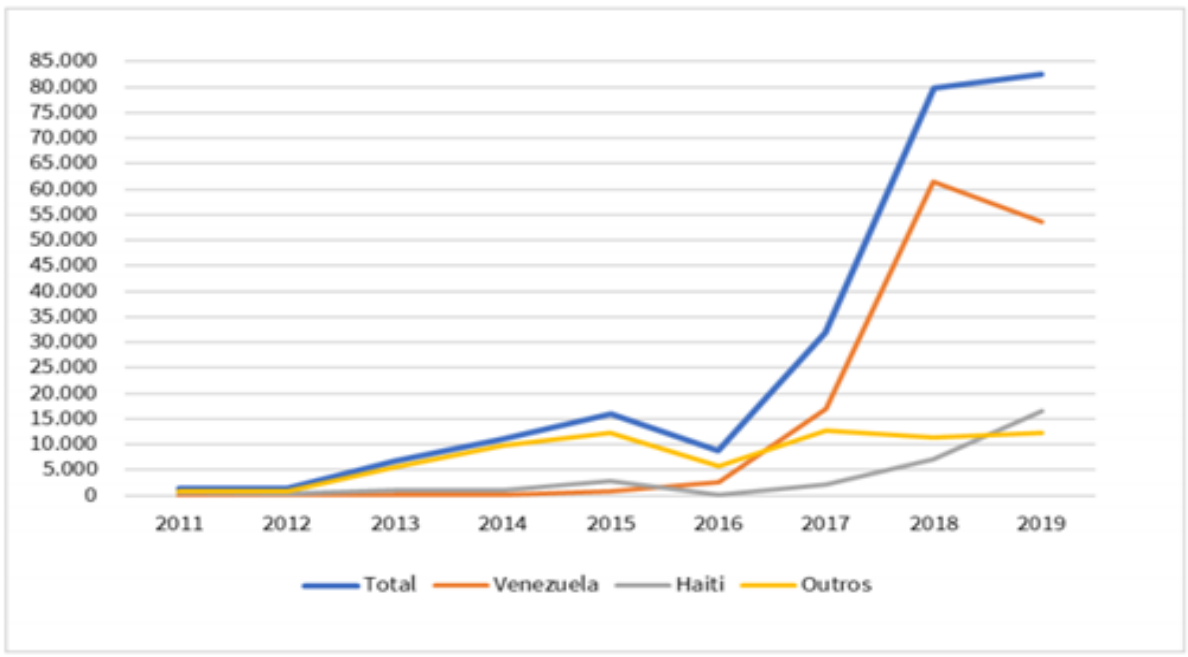

Fonte: Elaborado pelo OBMigra, a partir dos dados da Polícia Federal, solicitações de reconhecimento da condição de refugiado.

O Gráfico 1 aponta o número de solicitações de reconhecimento da condição de refugiado, no Brasil de 2011 a 201, com destaque para a Venezuela que teve um aumento acentuado nos ano de 2016 a 2018, chegando a 60 mil pedidos.

O Estado de Mato Grosso do Sul apresenta uma grande faixa de fronteira com outros países da América do Sul, como Paraguai e Bolívia. Essa faixa tem 150 quilômetros de largura e soma 143 mil quilômetros quadrados, ou $40 \%$ dos 357,1 mil quilômetros quadrados, que formam o território sul-mato-grossense. (IBGE, 2019).

O Mato Grosso do Sul representa para alguns imigrantes o destino final de uma jornada em busca de uma vida melhor, porém, para outros é apenas um corredor de passagem para outros grandes centros urbanos do Brasil como São Paulo e Rio de Janeiro. (NICOLAU, 2016, p. 03). A maioria dos imigrantes presentes no referido estado tem origem do Paraguai e Bolívia e em uma escala menor haitianos, venezuelanos, colombianos, bengalis e africanos. (IPEA, 2015, p. 90).

Tal estado também apresenta uma modalidade de migração que retardou a ser reconhecida pelo Brasil, a chamada migração humanitária. Essa migração, estabeleceu uma grande entrada de bengalis (oriundos de Bangladesh), que entram pela Bolívia e adquirem documentos falsos, sendo atravessados pelos "coiotes" até o Brasil. (NICOLAU, 2016, p. 05). 
Os municípios do estado de Mato Grosso do Sul, como Campo Grande, Ponta Porã, Corumbá e Dourados apresentaram diversas dificuldades nas políticas públicas estaduais e nas interações dos agentes de fronteira, como a insuficiência dos recursos humanos para trabalhar com o fluxo migratório, falta de orientação para a população sobre a problemática das migrações internacionais no âmbito nacional para evitar a violência e a discriminação contra os migrantes refugiados. (IPEA, 2015).

Quadro 4 - Movimentação de trabalhadores solicitantes de reconhecimento da condição de refugiado e refugiados no mercado de trabalho formal, segundo Brasil, Grandes Regiões e Unidades da Federação, 2011 - 2019.

\begin{tabular}{|c|c|c|c|}
\hline \multirow{2}{*}{$\begin{array}{c}\text { Grandes Regiobs } \\
\text { Unidades da Federaça }\end{array}$} & \multicolumn{3}{|c|}{ Total } \\
\hline & Admissobes & Desfligamentos & Saldo \\
\hline Brasill & 69.131 & 43.560 & 25.571 \\
\hline Norte & 9.028 & 5.037 & 3.991 \\
\hline Rondónia & 643 & 375 & 268 \\
\hline Acre & 46 & 28 & 18 \\
\hline Amazonas & 3.176 & 1.538 & 1.638 \\
\hline Roraima & 4.926 & 2.939 & 1.987 \\
\hline Pard & 181 & 113 & 68 \\
\hline Amapá & 26 & 17 & 9 \\
\hline Tocantins & 30 & 27 & 3 \\
\hline Nordeste & 1.101 & 610 & 491 \\
\hline Maranhāo & 49 & 22 & 27 \\
\hline Placuí & 31 & 18 & 23 \\
\hline Ceará & 456 & 296 & 160 \\
\hline Rio Grande do Norte & 64 & 33 & 31 \\
\hline Paraiba & 102 & 42 & 60 \\
\hline Permambuco & 159 & 77 & 82 \\
\hline Alagoas & 12 & 5 & 7 \\
\hline Sergipe & 28 & 15 & 13 \\
\hline Bahia & 200 & 102 & 98 \\
\hline Sudeste & 16.530 & 10.686 & 5.84 .4 \\
\hline Minas Gerais & 2.08 .4 & 1.177 & 907 \\
\hline Espiritoo Santo & 192 & 120 & 72 \\
\hline Rlio de Janeiro & 3.195 & 2.431 & 764 \\
\hline São Paulo & 11.059 & 6.958 & 4.101 \\
\hline Seat & 36.965 & 23.820 & 13.145 \\
\hline Paraná & 9.268 & 6.120 & 3.148 \\
\hline Santa Catarina & 23.113 & 6.907 & 6.206 \\
\hline Rio Grande do Sull & 1.4 .584 & 10.793 & 3.791 \\
\hline Centro-Oeste & 5.507 & 3.407 & 2.100 \\
\hline Mato Grosso do Sul & 1.107 & 478 & 629 \\
\hline Mato Grosso & 1.514 & 807 & 707 \\
\hline Goìas & 920 & 589 & 331 \\
\hline Distrito Federal & 1.966 & 1533 & 433 \\
\hline
\end{tabular}

Fonte: Elaborado pelo OBMigra, a partir dos dados do Ministério da Economia, base harmonizada RAIS-CTPS-CAGED, 2020.

O século XXI marca o aumento do fluxo migratório, de povos da América Latina em sua maioria, para o Brasil, apresentando uma certa alteração no perfil dos imigrantes que já constavam inseridos na sociedade brasileira. Observa-se, no quadro 4, que as regiões Sul e Sudeste são as que mais admitem trabalhadores refugiados. Estes imigrantes que passaram a entrar no território brasileiro são em sua maioria imigrantes pobres e trabalhadores, que 
dependem de acolhimento e políticas públicas para ter respostas às suas necessidades básicas.

Existe um grande fluxo de haitianos e africanos que estão se deslocando dentro de Mato Grosso do Sul, da capital Campo Grande para municípios do interior como Porto Murtinho, Aquidauana e Rio Brilhante, sobretudo atraídos pelo trabalho em áreas rurais e subempregos informais. (IPEA, 2015 p. 91).

Para atuar no combate a exploração dos imigrantes refugiados trabalhadores em áreas remotas do estado, foi criado o Comitê Estadual para Refugiados, Migrantes e Apátridas do Mato Grosso do Sul que está ligado à Secretaria de Estado de Direitos Humanos e à Assistência Social e Trabalho (Sedhast). O objetivo é amparar os imigrantes que chegam ao estado através das fronteiras e especializar um padrão de atendimento a essas pessoas, além de criar outros comitês locais nas diversas áreas de fronteira. (NICOLAU, 2016, p. 09).

\section{CONSIDERAÇÕES FINAIS}

A questão das migrações é um fenômeno recorrente no Mato Grosso Sul. A chegada dos migrantes é uma preocupação das autoridades brasileiras e estaduais, no sentido de acolher e evitar explorações dos trabalhadores refugiados, mas ainda esta situação não é o suficiente.

Deve-se analisar e compreender os contextos em que se dão às pessoas a condição de refugiadas, levando em consideração sua cultura, sua identidade e a sua adaptação a uma nova realidade e a um novo território, de modo que se faz necessário um maior incentivo a criação de novos comitês estaduais e regionais no Brasil e no estado de Mato Grosso do Sul, para intensificar o diálogo com a sociedade.

Para Da Silva (2012, p.88), "a realidade destas pessoas ainda está marcada por uma situação carente, do ponto de vista da inclusão em políticas públicas e oportunidades básicas necessárias para a reconstrução de uma vida". A dificuldade da inclusão do migrante em condição de refúgio nas vertentes básicas de território descritas por Haesbaert (2020) política, cultural, econômica e natural - é a causa de graves problemas sociais no território que recebe/acolhe essas pessoas.

Dessa forma, se faz necessário a criação e intensificação das discussões entre os órgãos responsáveis por receber os refugiados e a sociedade civil. Assim, promovendo-se a 
possibilidade de redução do preconceito e discriminação em relação aos imigrantes, desenvolvendo um equilíbrio humanitário no novo território que o acolhe para a formação de uma nova territorialidade e que contribua para o desenvolvimento local.

Dada à complexidade implícita dessa temática, este entendimento simples revela-se insuficiente nas movimentações migratórias. $\mathrm{O}$ aumento substancial do volume das atividades migratórias pelas diferentes motivações que têm ocorrido, pela história de vida narradas, pelo seguimento das rotas, pela imposição das determinações globais, as migrações internacionais podem ser visto em sua multifacetada visão, em constante metamorfose seja na adaptabilidade, seja nas situações circunstanciais do mundo em que acontecem.

\section{REFERÊNCIAS}

ACNUR. Global Trends 2020: Forced Displacement in 2019. Jun. 2020. Disponível em: <https://www.unhcr.org/globaltrends2019/>. Acesso em: 11 mai. 2021.

ALMEIDA, L. P. (Org.). Migrações, fronteira e refúgio: Mato Grosso do Sul na rota das migrações transnacionais. Campo Grande-MS: UCDB, 2017.

Appleyard, R. International Migration: Challenge for the Nineties. Genebra: IOM, 1991.

BRASIL. Ministério da Justiça e Segurança Pública. Refúgio em números. 3. ed. Brasília: MJSP, 2018.

Disponível

em: <https://portaldeimigracao.mj.gov.br/images/dados/Ref\%C3\%BAgio\%20em\%20n\%C3\%BAm eros/REF\%C3\%9AGIO\%20EM\%20N\%C3\%9AMEROS.pdf>. Acesso em: 11 mai. 2021.

BRASIL. Ministério da Justiça e Segurança Pública. Projeto de Cooperação. Disponível em: <https://app.powerbi.com/view?r=eyJrljoiNTQ4MTUONGItYzNkMi00M2MwLWFhZWMtMDB iM2I1NWVjMTY5liwidCI6ImU1YzM3OTgxLTY2NjQtNDEzNC04YTBjLTY1NDNkMmFmODBiZSIsI mMiOjh9>. Acesso em: 11 mai. 2021.

BOMTEMPO, D. C.; SPOSITO, E. S. Entre o Japão e o Brasil: a territorialidade dos migrantes, isseis e dekasseguis. In: SAQUET, M. A.; SPOSITO, E. S. (Org.). Territórios e territorialidades: teorias, processos e conflitos - 1.ed. São Paulo: Expressão Popular: UNESP. Programa de PósGraduação em Geografia, 2008.

CAVALCANTI, L; OLIVEIRA, FURTADO, A; DICK, P; QUINTINO, F; MACEDO, M. Acompanhamento de fluxo e empregabilidade dos imigrantes no Brasil: Relatório Mensal do OBMigra Ano 1, Número 1, janeiro de 2020/ Observatório das Migrações Internacionais; Brasília, DF: OBMigra, 2020. Disponível em:

<https://portaldeimigracao.mj.gov.br/pt/dados/relatorios-mensais>. Acesso em: 5 mai. 2021. 
CAVALCANTI, L; OLIVEIRA, T.; MACEDO, M., Imigração e Refúgio no Brasil. Relatório Anual 2019. Série Migrações. Observatório das Migrações Internacionais; Ministério da Justiça e Segurança Pública/ Conselho Nacional de Imigração e Coordenação Geral de Imigração Laboral. Brasília, DF: OBMigra, 2019.

Cohen, R. Globalização, migração internacional e cosmopolitismo quotidiano. In: Barreto A. (org.),Globalização e migrações. Lisboa: Imprensa de Ciências Sociais, 2005.

DA SILVA, César Augusto S. (org.). Direitos Humanos e Refugiados. Dourados: Ed. UFGD, 2012.

DI MÉO, G. Geographie sociale et territoires. Paris: Nathan, 1998. In: HAESBAERT, R. O mito da desterritorialização: do "fim dos territórios" à multiterritorialidade. 12a ed. - Rio de Janeiro: Bertrand Brasil, 2020.

Fairchild, H. P. Immigration: A World Movement and its American Significance New York. Macmillan, 1925

HAESBAERT, R. 0 mito da desterritorialização: do "fim dos territórios" à multiterritorialidade. 12a ed. - Rio de Janeiro: Bertrand Brasil, 2020.

IBGE - Instituto Brasileiro de Geografia e Estatística. Atualização dos dados geográficos de estados e municípios brasileiros. Disponível em: $<$ https://agenciadenoticias.ibge.gov.br/agencia-sala-de-imprensa/2013-agencia-denoticias/releases/27737-ibge-atualiza-dados-geograficos-de-estados-e-municipiosbrasileiros>. Acesso em: 11 mai. 2021.

INSTITUTO DE PESQUISA ECONÔMICA APLICADA (IPEA). Migrantes, Apátridas e Refugiados: subsídios para o aperfeiçoamento de acesso a serviços, direitos e políticas públicas no Brasil. Série Pensando o Direito, n. 57, 2015.

MAGALHÃES, L. F.; ZUBEN, C. V.; PARISE, P.; DEMÉTRIO, N.; DOMENICONI, J. (Org.). Migrações internacionais e a pandemia de Covid-19. Campinas: Núcleo de Estudos de População "Elza Berquó" - Nepo/Unicamp, 2020, 636p.

NICOLAU, P. C. Ausência de políticas de integração legislativas de proteção aos refugiados na região sul-americana a partir do caso do Mato Grosso do Sul, 2016.

PEREIRA JÚNIOR, J. R. et al. Refúgio no Brasil: integração de refugiados e solicitantes de refúgio em Brasília (2019). 2020.

RADOMSKY, G. F. W. et al. Desenvolvimento Rural: do agrícola ao territorial. In: NIEDERLE, P. A.; RANDOMSKY, G. F. W. (Orgs.). Introdução às teorias do desenvolvimento. Porto Alegre: Editora da UFRGS, 2016.

PETERSEN, W. A General Typology of Migration. American Sociological Review, 23(3), 256266, 1958. 
PEIXOTO, J. As migrações dos quadros altamente qualificados em Portugal. Fluxos migratórios inter-regionais e internacionais e mobilidade intra-organizacional. Tese de Doutoramento apresentada ao Instituto Superior de Economia e Gestão da Universidade Técnica de Lisboa, Lisboa, Portugal, 1998.

PORTES, A. Migrações internacionais. Origem, tipos e modos de incorporação. Oeiras: Celta, 1999.

SANTOS, M. Por uma outra globalização: do pensamento único à consciência universal. 31a ed. - Rio de Janeiro: Record, 2020.

SAQUET, M. A. Por uma abordagem territorial. In: SAQUET, M. A.; SPOSITO, E. S. (Org.). Territórios e territorialidades: teorias, processos e conflitos - 1.ed. São Paulo: Expressão Popular: UNESP. Programa de Pós-Graduação em Geografia, 2008.

SILVA, C. A. S.; SERPA, P. F. O fluxo migratório no Estado de Mato Grosso do Sul: recepção dos refugiados e de imigrantes internacionais. R. METAXY, Rio de Janeiro, v.2, n.1, p. 31-55, 2019.

SILVA, G. J; CAVALCANTI, L; OLIVEIRA, T; MACEDO, M. Refúgio em Números, 5a Ed. Observatório das Migrações Internacionais; Ministério da Justiça e Segurança Pública/ Comitê Nacional para os Refugiados. Brasília, DF: OBMigra, 2020. 